\title{
Characterization of oxygen radical formation mechanism at early cardiac ischemia
}

\author{
$X Z^{\prime h u}{ }^{1,2}$ and $L$ Zuo*,2,3,4
}

Myocardial ischemia-reperfusion (I/R) causes severe cardiac damage. Although the primary function of oxymyoglobin (Mb) has been considered to be cellular $\mathrm{O}_{2}$ storage and supply, previous research has suggested that $\mathrm{Mb}$ is a potentially protective element against I/R injury. However, the mechanism of its protective action is still largely unknown. With a real-time fluorescent technique, we observed that at the onset of ischemia, there was a small burst of superoxide $\left(\mathrm{O}_{2}^{--}\right)$release, as visualized in an isolated rat heart. Thus, we hypothesize that the formation of $\mathrm{O}_{2}^{--}$correlates to $\mathrm{Mb}$ due to a decrease in oxygen tension in the myocardium. Measurement of $\mathrm{O}_{2}^{--}$production in a Langendorff apparatus was performed using surface fluorometry. An increase in fluorescence was observed during the onset of ischemia in hearts perfused with a solution of hydroethidine, a fluorescent dye sensitive to intracellular $\mathrm{O}_{2}^{--}$. The increase of fluorescence in the ischemic heart was abolished by a superoxide dismutase mimic, carbon monoxide, or by Mb-knockout gene technology. Furthermore, we identified that $\mathrm{O}_{2}^{--}$was not generated from the intracellular endothelium but from the myocytes, which are a rich source of $\mathrm{Mb}$. These results suggest that during the onset of ischemia, $\mathrm{Mb}$ is responsible for generating $\mathrm{O}_{2}^{--}$. This novel mechanism may shed light on the protective role of $\mathrm{Mb}$ in $\mathrm{l} / \mathrm{R}$ injury. Cell Death and Disease (2013) 4, e787; doi:10.1038/cddis.2013.313; published online 5 September 2013

Subject Category: Experimental Medicine

Ischemia-reperfusion (I/R) injuries are recognized as one of the key factors in the exacerbation of cardiovascular diseases. ${ }^{1}$ Ischemic preconditioning (IPC), using a few cycles of short ischemic period, is shown to protect against $\mathrm{I} / \mathrm{R}$ damage in cardiac muscles. ${ }^{2}$ It has been speculated that IPC could correlate to signaling cascades initiated by reactive oxygen species (ROS), ${ }^{2}$ yet, the exact redox mechanisms of IPC has not been thoroughly elucidated. For example, there is a lack of direct evidence for ROS formation measured at the onset of ischemia in an intact heart. The source of ROS formation has not been determined during early ischemia, which correlates to the timeframe of IPC.

Oxymyoglobin $(\mathrm{Mb})$ has been shown to have a role in alleviating I/R injuries. ${ }^{3,4}$ However, the complete mechanism of its protective action is still unclear. $\mathrm{Mb}$ has one $\mathrm{O}_{2}$ binding site consisting of heme, which is a prosthetic group containing an iron $\left(\mathrm{Fe}\right.$ ) ion. Mb functions as both an $\mathrm{O}_{2}$ storage site under normal conditions and an $\mathrm{O}_{2}$ supply during temporary deficits. ${ }^{5}$ The oxygen binding properties of $\mathrm{Mb}$ are contingent upon the oxidation state of $\mathrm{Fe}$ within the heme group. Ferrous heme $\left(\mathrm{Fe}^{2+}\right)$ is found in the reduced form of $\mathrm{Mb}$ and can function as an $\mathrm{O}_{2}$ binding site. In contrast, when ferric heme $\left(\mathrm{Fe}^{3+}\right)$ is present in the $\mathrm{Mb}$ complex, $\mathrm{O}_{2}$ binding cannot occur.
One key physiological result of $\mathrm{Fe}^{2+}$ oxidation is the generation of superoxide $\left(\mathrm{O}_{2}^{\circ-}\right)$ through the following reaction: ${ }^{6}$

$$
\mathrm{Fe}^{2+}+\mathrm{O}_{2} \rightarrow \mathrm{Fe}^{3+}+\mathrm{O}_{2}^{--}
$$

$\mathrm{O}_{2}^{\circ-}$, a type of ROS, is a biologically important signaling molecule involved in many physiological and pathological processes, including hypoxia, heat stress, septic shock, and muscle dysfunction. ${ }^{7}$ Increased $\mathrm{O}_{2}^{\circ-}$ formation following ischemia is associated with the pathogenesis of $\mathrm{I} / \mathrm{R}$ injury. ${ }^{8}$ Oxidative damage during $\mathrm{I} / \mathrm{R}$ is commonly linked to the formation of $\mathrm{O}_{2}^{--}$and generally attributed to reperfusion, a process in which restored flux of $\mathrm{O}_{2}$ encounters a highly reduced environment of ischemic tissue, leading to tissue damage. ${ }^{9,10}$ As the correlation between $\mathrm{O}_{2}^{\circ-}$ formation and reperfusion injury has been well studied in the past decade, ${ }^{11-13}$ we are primarily focused on $\mathrm{O}_{2}^{--}$formation at the early phase of ischemia, which is understudied.

$\mathrm{O}_{2}^{\circ-}$ and $\mathrm{O}_{2}^{\circ-}$-derived oxidants can be formed during the early period of reperfusion. ${ }^{1}$ Some research showed that this oxidative burst is attributed to the accumulation of xanthine during ischemia and the activation of xanthine oxidase (XO) enzyme at reperfusion. ${ }^{9}$ Other researchers suggested that the mitochondrion is a primary source. ${ }^{14}$ However, $\mathrm{O}_{2}^{--}$formation

\footnotetext{
${ }^{1}$ Department of Pulmonary Medicine, Ruijin Hospital, School of Medicine, Shanghai Jiao Tong University, Shanghai, China; ${ }^{2}$ Department of Medicine, School of Medicine, UCSD, La Jolla, CA, USA; ${ }^{3}$ Molecular Physiology and Biophysics Laboratory, Oakland University, Rochester, MI, USA and ${ }^{4}$ Ohio State University College of Medicine, Molecular Physiology and Rehabilitation Research Lab, OSU Wexner Medical Center, Columbus, OH, USA

${ }^{*}$ Corresponding author: L Zuo, Ohio State University College of Medicine, Molecular Physiology and Rehabilitation Research Lab, OSU Wexner Medical Center, 333 W 10th, Columbus, OH 43210, USA. Tel: +1 614292 5740; Fax: +1 614292 0216; E-mail: zuo.4@osu.edu

Keywords: ischemia; confocal; rat; oxymyoglobin

Abbreviations: I/R, ischemia-reperfusion; $\mathrm{O}_{2}^{--}$, superoxide; IPC, ischemic preconditioning; ROS, reactive oxygen species; $\mathrm{Fe}^{2+}$, ferrous heme; $\mathrm{Fe}^{3+}$, ferric heme; XO, xanthine oxidase; Myo - I - , Mb knockout; WT, wild type; DHE, dihydroethidium; ET, ethidium; SOD, superoxide dismutase; MnTMPyP, Mn(III)tetrakis(1-methyl-4pyridyl) porphyrin; FLI-IB4, fluorescein lectin I-isolectin B4; RU, relative unit; RU/s, relative unit per second; FAD, flavine adenine dinucleotide; HPC, hypoxic preconditioning; PI3K, phosphatidylinositol 3-kinase; $\mathrm{K}_{\mathrm{ATP}}$ channel, ATP potassium channel; GSK-3 $\beta$, glycogen synthase kinase-3 $\beta$; mPTP, mitochondrial permeability transition pore
}

Received 29.3.13; revised 12.6.13; accepted 03.7.13; Edited by A Finazzi-Agró 
has not been reported during the onset of myocardial ischemia in a Langendorff heart model. ${ }^{15}$ Furthermore, the mechanism of $\mathrm{O}_{2}^{\circ-}$ production during early ischemic period has been largely overlooked. It is likely that this may be correlated to IPC, which employs brief cycles of ischemia and has been shown to have a critical role in cardiac therapeutics. ${ }^{2}$ The production of $\mathrm{O}_{2}^{--}$at the early ischemia may possibly protect an ischemic heart from further damage during reperfusion via IPC signaling cascades. ${ }^{2}$

We have previously identified a large burst of $\mathrm{O}_{2}^{--}$formation during reperfusion in both in vivo and in vitro heart models. ${ }^{1,16}$ Thus, the current research is primarily focused on the $\mathrm{O}_{2}^{\circ-}$ formation at early ischemia. We have designed an innovative study which demonstrates that $\mathrm{O}_{2}^{--}$formation occurs during the onset of ischemia (within the first min). Using an isolated perfused rat heart model, the intracellular $\mathrm{O}_{2}^{\circ-}$ formation is detected by a fluorescent $\mathrm{O}_{2}^{\circ-}$ probe. We hypothesize that $\mathrm{Mb}$ oxidation $\left(\mathrm{Fe}^{2+} \rightarrow \mathrm{Fe}^{3+}\right)$ coupled with the production of $\mathrm{O}_{2}^{\circ-}$ may occur during early ischemia. The current study may help to develop new therapeutic preconditioning methods for $\mathrm{I} / \mathrm{R}$ injuries, which is consistent with previous research showing that $\mathrm{Mb}$ is a potentially protective element during I/R through redox pathways. ${ }^{3}$

\section{Results}

Previous studies have chemically demonstrated that the autoxidation reaction of $\mathrm{Mb}\left(\mathrm{Fe}^{2+}\right)$ to $\mathrm{MetMb}\left(\mathrm{Fe}^{3+}\right)$ results in the accompanied formation of $\mathrm{O}_{2}^{\bullet-}{ }^{17,18} \mathrm{In}$ order to determine whether $\mathrm{O}_{2}^{\circ-}$ production in real time occurs within the ischemic cardiac tissue, ethidium (ET) fluorescence was monitored in an isolated rat heart with or without ischemia treatment, and recorded in a relative unit using the surface fluorometric method described above. As shown in Figure 1, a rapid increase in ET fluorescence ( $\sim 18 \%$ of baseline from autofluorescence) was detected within $3 \mathrm{~min}$ after the onset of ischemia and reached $\sim 24 \%$ of baseline at $9 \mathrm{~min}$ of the ischemic period, as compared with all other treatments $(n=5$; $P<0.05)$. Meanwhile, autofluorescence decreased in nonloaded ischemic hearts $(\sim 10 \%$ at $20 \mathrm{~s}$ from the start of

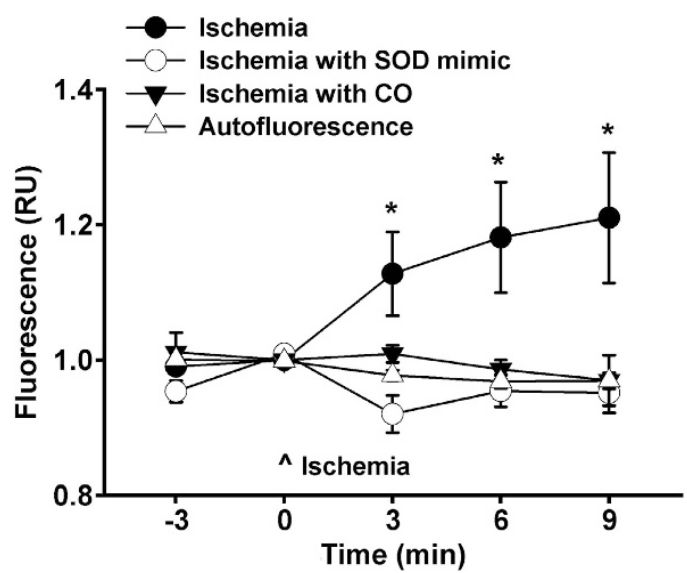

Figure 1 Fluorescence levels over the time course of $9 \mathrm{~min}$ in ischemia, ischemia with $\mathrm{CO}$ treatment, ischemia with SOD mimic treatment, and autofluorescence. ${ }^{\star} P<0.05$, ischemia versus all other groups ischemia; $n=3$ ). This change in the basal fluorescence was likely due to the autofluorescence of intracellular flavine adenine dinucleotide (FAD), which decreased during the course of ischemia or hypoxia in striated muscles. ${ }^{19}$ To confirm that the elevated ET fluorescence was due to $\mathrm{O}_{2}^{\circ-}$ production in the ischemic heart, superoxide dismutase (SOD) mimetic was used, and it turned out that the increase of ET fluorescence in the ischemia heart was subsequently abolished $(n=8)$. To further analyze the involvement of $\mathrm{Mb}$ in $\mathrm{O}_{2}^{\circ-}$ production, we treated the hearts with a $\mathrm{CO}$ solution $(10 \%)$ that potentially blocks ferro-metallo proteins such as $\mathrm{Mb}$ from binding to oxygen, which chemically eliminates the formation of $\mathrm{O}_{2}^{\circ-} \cdot{ }^{6} \mathrm{CO}$ treatment reduced $\mathrm{ET}$ fluorescence in the ischemic heart compared with the pure ischemia group $(n=4)$. These results strongly indicate that $\mathrm{Mb}$ is involved in $\mathrm{O}_{2}^{\circ-}$ formation in the heart at the early onset of ischemia.

As we observed significant $\mathrm{O}_{2}^{--}$generation within 3 min of ischemia (Figure 1), it is critical to explore this phenomenon in a micro time course during a 1-min period, as illustrated in Figure 2. During the first $12 \mathrm{~s}$ of ischemia, there was no obvious change of ET fluorescence. However, at $16 \mathrm{~s}$, the fluorescence started to increase to $\sim 12 \%$ of baseline compared with autofluorescence and reached a peak of $\sim 18 \%$ at $20 \mathrm{~s}$ after ischemia. These increases were significant compared with all other groups $(n=3 ; P<0.05)$, which suggest that $\mathrm{O}_{2}^{\bullet-}$ generation in the heart is an immediate response to ischemia.

Mean fluorescence rate (averaged by three rat hearts) was calculated over a micro time course of $60 \mathrm{~s}$ immediately following the ischemia period, and was displayed in a relative unit per second. In the ischemia-only group, there are two large spikes (representing rapid increases) and one small spike (for slow increases) on the ET signal rate. Among these three spikes, the first one appears as early as $8 \mathrm{~s}$, the middle one shows at $24 \mathrm{~s}$, and the last one (the smallest) occurs at $\sim 44 \mathrm{~s}$. This clearly demonstrated that two large $\mathrm{O}_{2}^{\circ-}$ bursts occurred within $24 \mathrm{~s}$ from the start of ischemia (Figure $3 a$ ). We also noticed that the second peak was $\sim 25 \%$ greater than the first one. These spikes were suppressed in both SOD mimic (Figure $3 b$ ) and $\mathrm{CO}$ groups (Figure $3 \mathrm{c}$ ), which indicated a

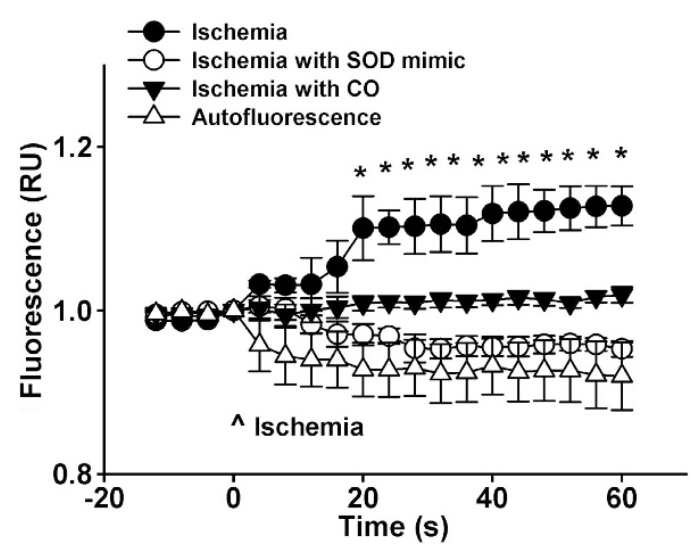

Figure 2 Zoomed fluorescence levels over the micro time course of $60 \mathrm{~s}$ in ischemia, ischemia with CO treatment, ischemia with SOD mimic treatment, and autofluorescence. ${ }^{*} P<0.05$, ischemia versus all other groups 


\section{a}

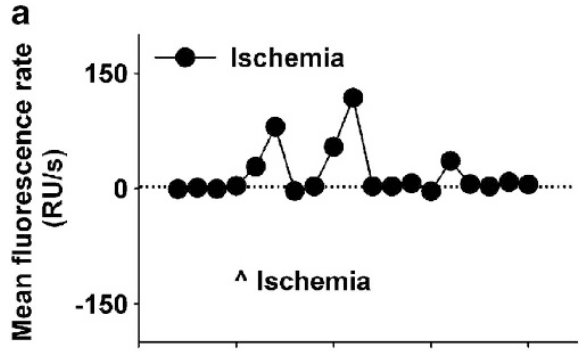

C

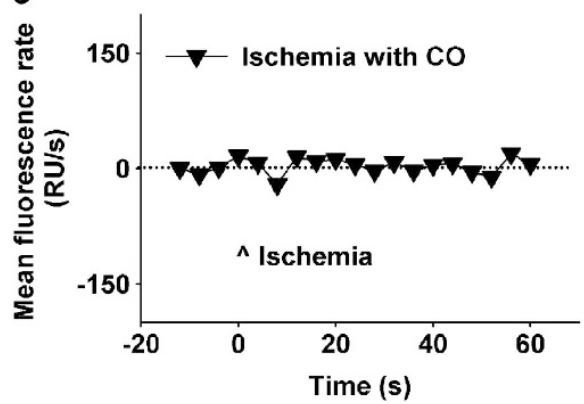

b

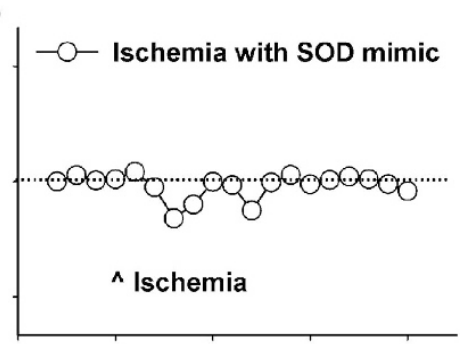

d

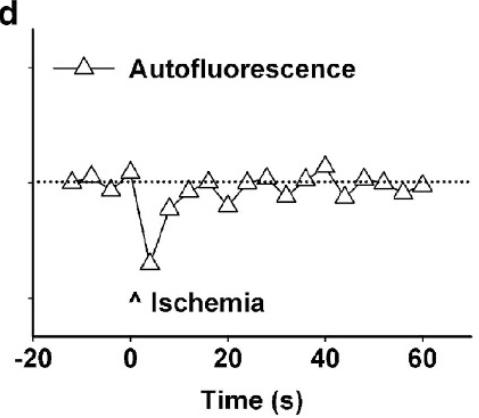

Figure 3 Mean fluorescence rate (fluorescence change per second; relative unit per second, RU/s) over the time course of $60 \mathrm{~s}$ from the start of ischemia in rat heart. (a) mean fluorescence rate in the ischemia-only group. (b) mean fluorescence rate in SOD mimic treatment group. (c) mean fluorescence rate in $\mathrm{CO}$ treatment group. (d) mean fluorescence rate in autofluorescence group $(n=3)$

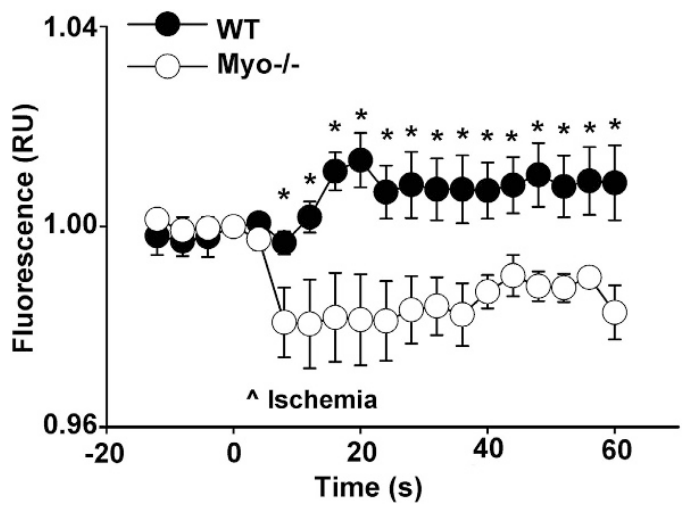

Figure 4 Fluorescence levels over the time course of $60 \mathrm{~s}$ from the start of ischemia. ${ }^{*} P<0.05, n=4$; Mb-knockout (Myo $-/-$ ) mice versus wild-type (WT) mice

possible involvement of $\mathrm{Mb}$ in determination of $\mathrm{O}_{2}^{\bullet-}$ generation rate. There were no positive spikes in baseline autofluorescence, but a large negative spike was observed, showing that $\mathrm{O}_{2}^{\circ-}$ signal should overcome the autofluorescence decline first before it rises up (as shown in the ischemia group). Thus, we underestimated the increased $\mathrm{O}_{2}^{--}$signal, which would otherwise have been more significant (Figures 2 and 3).

In order to further confirm the role of $\mathrm{Mb}$ in $\mathrm{O}_{2}^{\circ-}$ generation in other rodent models, Myo - / - mice and wild-type mice were used following a similar protocol in the rat experiments. As early as $20 \mathrm{~s}$ from the start of ischemia, fluorescence was enhanced ( $\sim 4 \%$ greater than baseline autofluorescence) and maintained throughout the ischemic period in wild-type mice compared with Myo $-I-$ mice $(n=4 ; P<0.05$; Figure 4).
Interestingly, fluorescence from Myo - / - mice decreased in a manner similar to autofluorescence as shown in Figure 4, suggesting that $\mathrm{Mb}$ have an important role in $\mathrm{O}_{2}^{\circ-}$ generation in early ischemia.

Similar to the rat study, the mean rate of increase of ROS fluorescence during the first $60 \mathrm{~s}$ of ischemia was calculated in the transgenic mouse model. In the wild-type mice group, a spike in the mean rate of ET signal was observed as early as $16 \mathrm{~s}$ (Figure 5a). However in Myo-/- group, this spike disappeared, but a negative spike occurred at $4 \mathrm{~s}$ (Figure $5 \mathrm{~b}$ ), which is similar to the response curve from the autofluorescence in rat (Figure $3 d$ ).

To determine the cellular location and the source of $\mathrm{O}_{2}^{--}$ production, we analyzed ET fluorescence in an ischemic heart using confocal microscopy via dual-labeling of the myocytes and endothelial cells. Figure $6 a$ showed that the baseline fluorescence before ischemia treatment is kept at a minimal level. Figures $6 b$ and $c$ represent the fluorescent images at $3 \mathrm{~min}$ of ischemia, which are brighter in red compared with Figure $6 \mathrm{a}$. This suggests that the early generation of $\mathrm{O}_{2}^{\circ-}$ in response to ischemia. As shown in Figure 6c, the increase of ischemia-induced fluorescence originated from cardiomyocytes (Figures $6 \mathrm{~b}$ and $\mathrm{c}$; the red represents ROS formation and the green represents endothelium), but not endothelial cells (shown in green in Figure 6c) because there was clearly no overlap between the two dyed areas. These results confirmed that $\mathrm{O}_{2}^{\circ-}$ formation occurred in the Mb-rich cardiac muscle tissue but not in the endothelial tissue.

\section{Discussion}

This is the first study demonstrating that $\mathrm{Mb}$ is a major source of $\mathrm{O}_{2}^{\circ-}$ formation at the onset of ischemia in a Langendorff 
heart model. Our data provide an insight into the molecular mechanism of IPC which utilizes ROS generated during early ischemia to protect the cardiomyocytes via redox signaling cascades. $^{2}$

The generation of reactive, partially reduced oxygen species has been well established as a causative factor for tissue damage that occurs during reperfusion of a previously ischemic tissue. ${ }^{20}$ Protection against oxidant injury is particularly meaningful during the early reperfusion period after an ischemic insult, which is characterized by the sudden formation of large amounts of $\mathrm{O}_{2}^{\bullet-}$.

Former research assumed that sources such as $\mathrm{XO}$, NADPH oxidase, and the mitochondrial electron transport chain are the primary sources of ROS development during
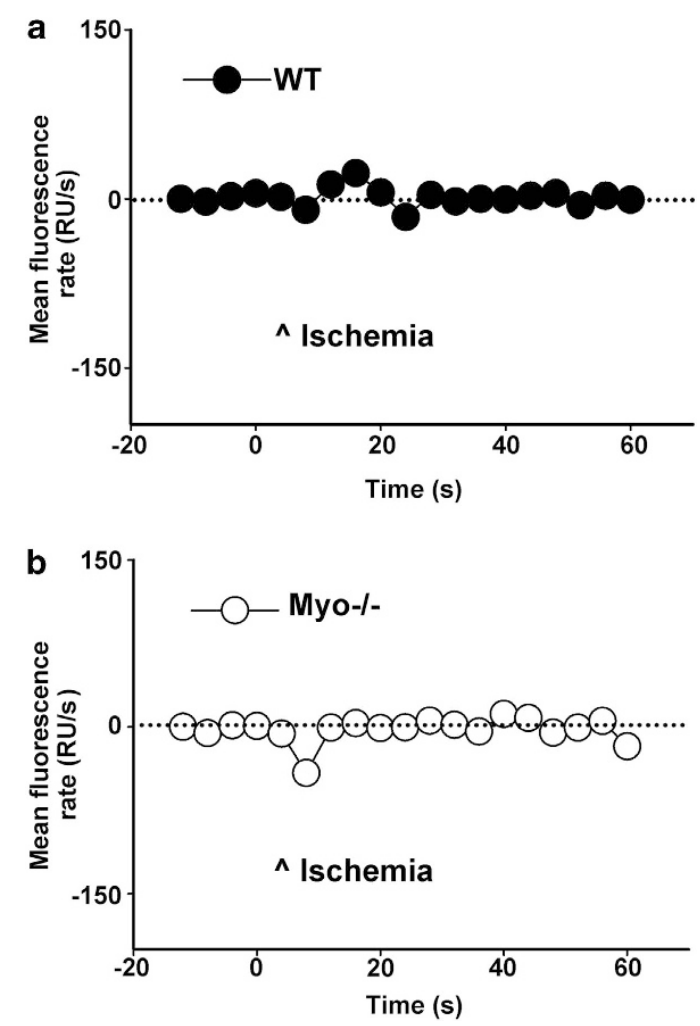

Figure 5 Mean fluorescence rate (fluorescence change per second; RU/s) over the time course of $60 \mathrm{~s}$ from the start of ischemia in a mouse heart. (a) mean fluorescence rate in WT mice. (b) mean fluorescence rate in Myo $-/-$ mice $(n=4)$ ischemia. ${ }^{15,21,22}$ Other research has shown that ROS formation occurs during extended simulated ischemia $(1 \mathrm{~h})$ using cell culture system. ${ }^{15}$ However, there is no convincing evidence showing any ROS generation in the early stage of cardiac ischemia in a whole-heart model. Yet, the enzyme XO, which oxidizes purines such as hypoxanthine and xanthine to produce uric acid and $\mathrm{O}_{2}^{--}$, has received a great deal of experimental attention as a source of $\mathrm{O}_{2}^{--}$during reperfusion, ${ }^{23}$ but not at the onset of ischemia. Likewise, the mitochondrion is an additional possible source of ROS generation, but has not previously been reported its correlation to ROS formation during early ischemia. ${ }^{24}$

As questions have remained regarding the production of ROS at the early onset of ischemia, our work has filled the gap of previous knowledge by investigating the potential role of $\mathrm{Mb}$ in the production of ROS during ischemia in a Langendorff model. $\mathrm{Mb}$ is a ubiquitous protein that is present in the cardiac muscle at relatively high concentrations, and has also been viewed to facilitate the diffusion of $\mathrm{O}_{2}$ in the cardiac muscle. ${ }^{25}$ Even under normal conditions, $\mathrm{Mb}$ undergoes reactions that generate metMb $\left(\mathrm{Fe}^{3+}\right)$ species and $\mathrm{O}_{2}^{\circ-26}$ Yet, the function of $\mathrm{Mb}$ has not been previously identified as a potential factor in ROS formation during ischemia. Therefore, the demonstration of $\mathrm{O}_{2}^{--}$production by $\mathrm{Mb}$ gives a new perspective on the mechanism of $\mathrm{O}_{2}^{\circ-}$ formation at the onset of ischemia.

From our previous research ${ }^{16}$ and current data, this amount of $\mathrm{O}_{2}^{--}$is small compared with reperfusion-induced ROS, which is ideal for preconditioning signal. ${ }^{2}$ In addition, our protocol used $\mathrm{CO}$ treatment coupled with ischemia to verify that $\mathrm{MbO}_{2}$ autoxidation is a primary source of $\mathrm{O}_{2}^{--}$generation. As shown in Figures 1 and 2, the fluorescence levels were significantly lower in the ischemia with $\mathrm{CO}$ model compared with ischemia alone. As there is no hemoglobin in our Langendorff perfusion apparatus, the binding of $\mathrm{CO}$ to the cardiac $\mathrm{Mb}$ in our set up effectively prevents $\mathrm{O}_{2}^{--}$formation. Figure 6 confirmed that $\mathrm{O}_{2}^{\circ-}$ does not originate from $\mathrm{Mb}$ deficient vasculatures but rather from the myocytes, whereby the amount of $\mathrm{Mb}$ is abundant.

At $\sim 20 \mathrm{~s}$ from the start of ischemia, the increase of $\mathrm{O}_{2}^{\bullet-}$ signal in rat models $(\sim 18 \%>$ baseline autofluorescence, Figure 2) was larger than the mouse model ( $\sim 4 \%>$ baseline autofluorescence, Figure 4). Similarly, in the curves from the mean rate of ROS fluorescence, the rat model had two large $\mathrm{O}_{2}^{--}$bursts (Figure 3 ), whereas the mouse model only had one, which is $\sim 60 \%$ smaller (Figure 5 ). This difference is possibly owing to the usage of different animal models (rat
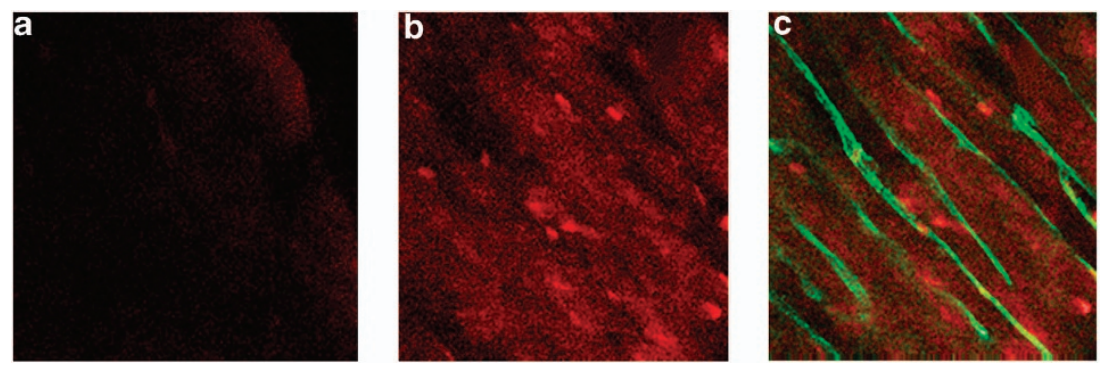

Figure 6 Localization of $\mathrm{O}_{2}^{--}$formation during the onset of ischemia on the heart surface using confocal microscopy. (a) heart baseline fluorescence before ischemia. (b) $\mathrm{O}_{2}^{--}$generation in the $\mathrm{HE}$-loaded heart within 3 min during ischemia. (c) $\mathrm{O}_{2}^{--}$generation in hearts treated with dual-fluorescence probes (HE and fluorescein lectin I-isolectin B4 (FLI-IB4)), showing that $\mathrm{O}_{2}^{--}$production is within the cardiomyocytes, not in the endothelial vessels 
versus mouse). We also noticed that CO only blocked $\sim 70 \%$ of the ischemic signal, whereas almost $100 \%$ of the signal was inhibited by the SOD mimic within $20 \mathrm{~s}$ after the ischemia started in the rat model (Figure 2). We initially speculated that mitochondria or other ROS generators accounted for this $\sim 30 \%$ difference in the blockage of $\mathrm{O}_{2}^{\circ-}$ signals. However, this is unlikely because the ROS signal was completely abolished in the transgenic Myo - / - mouse model (Figures 4 and 5), suggesting the key role of $\mathrm{Mb}$ in $\mathrm{O}_{2}^{\circ-}$ formation. Thus, it is probably due to the partial blockage of $\mathrm{Mb}$ by $\mathrm{CO}$ as a relatively low dosage of $\mathrm{CO}$ as well as a short incubation period was used. Yet, it is difficult to increase this dosage to a greater level as higher levels of $\mathrm{CO}$ could directly cause irreversible cardiac failure.

There are other limitations associated with CO blockage. As the $\mathrm{Ki}$ of $\mathrm{CO}$ for cytochrome oxidase is of the same order as the $\mathrm{Km}$ for oxygen, ${ }^{27}$ the $10 \%$ proportion of $\mathrm{CO}$ in the gas phase would result in about $10 \%$ inhibition of cytochrome oxidase under aerobic conditions. However, when oxygen is depleted upon ischemia, the addition of $\mathrm{CO}$ not only blocks $\mathrm{Mb}$ function but also inhibits mitochondrial cytochrome oxidase during ischemia. Thus, it is critical to perform Myo - / - mice experiments to verify the role of $\mathrm{Mb}$ in our setup.

During the first $60 \mathrm{~s}$ from the start of ischemia, the $\mathrm{O}_{2}^{--}$ formation rate is not constant, that is, the generation of $\mathrm{O}_{2}^{--}$was not continuous, including the first two larger ROS bursts at $8 \mathrm{~s}$ and $24 \mathrm{~s}$ respectively, followed by an extremely small burst ( $\sim$ one-third of the previous one) at $44 \mathrm{~s}$ (Figure 3a). This suggested a possible involvement of endogenous antioxidant enzymes such as SOD, catalase, and glutathione peroxidase during early ischemia, which gradually attenuated the $\mathrm{O}_{2}^{\circ-}$ formation rate. ${ }^{19}$

From a clinical perspective, an oxidative burst occurs in the myocardium during open heart surgery as a result of reperfusion injury following ischemia. ${ }^{28}$ This oxidative stress overwhelms the antioxidant defense system and leads to DNA damage and protein degradation. ${ }^{28}$ Hypoxic preconditioning (HPC) partially simulates early hypoxia or ischemia by using a few cycles of short hypoxia treatment to protect skeletal muscles from oxidative damage. ${ }^{29}$ Our previous work further identified a plausible cellular signaling mechanism of HPC involves a phosphatidylinositol 3-kinase (PI3K), which also has a crucial role in cardiomyocyte protection from $\mathrm{I} / \mathrm{R}$ injury. ${ }^{29,30}$ Similar to HPC, IPC uses a few short cycles of ischemia, which significantly protects cardiac muscle from I/R injury through the opening of mitochondrial ATP potassium channels (K $\mathrm{K}_{\text {ATP }}$ channel). ${ }^{2}$ IPC or HPC can potentially initiate the PI3K signaling pathway to inhibit glycogen synthase kinase $-3 \beta$, which has beneficial effects on cardiomyocytes, ${ }^{31}$ as the activation of glycogen synthase kinase- $3 \beta$ leads to mitochondrial permeability transition pore opening, therefore disrupting ATP synthesis. ${ }^{2}$

Interestingly, confocal data from previous HPC research illustrated that intramuscular ROS formation significantly decreases after HPC treatment, ${ }^{29}$ and thus it is likely that PI3K activated by HPC can enhance antioxidant defenses in the cardiac muscle as it has done in the skeletal muscle. Furthermore, the activation of mitochondrial $\mathrm{K}_{\text {ATP }}$ channels has been shown in several studies to have a role in preconditioning; ${ }^{32,33}$ however, it was recently suggested that the opening of mitochondrial $\mathrm{K}_{\text {ATP }}$ channels initiates the preconditioning by producing free radicals. ${ }^{34}$ Antioxidants applied before IPC or HPC treatment significantly decrease the cardioprotection during $\mathrm{I} / \mathrm{R}^{2}{ }^{2}$ These studies strongly suggest that the generation of free radicals such as $\mathrm{O}_{2}^{--}$during IPC is necessary to trigger an inherent protective mechanism of preconditioning. The oxygenation and deoxygenation of $\mathrm{Mb}$ and the resulting small formation of $\mathrm{O}_{2}^{\circ-}$ identified in our current research likely occurs during IPC. Our identification of Mb as a novel $\mathrm{O}_{2}^{\circ-}$ generator in cardiomyocyte ischemia gives it an anticipated role in cardioprotection for ischemic injuries.

Our result contradicts Schrader and group's ${ }^{35}$ previous study, which showed that $\mathrm{O}_{2}^{\circ-}$ production decreased to zero within seconds upon ischemia onset and stayed at such a level until reperfusion. Such a disparity may have been a result of the substantially different technology used in our study compared with that of the Schrader' experiments. Unlike the experiments conducted by Schrader and group's ${ }^{35}$, we utilized a fluorescent probe rather than a chemiluminescence probe lucigenin. Previous research has raised significant concerns on the effectiveness of lucigenin for the detection of $\mathrm{O}_{2}^{\bullet-}$. For instance, in various models, the fluorescent $\mathrm{O}_{2}^{\bullet-}$ probes appear to be sensitive in detecting residual $\mathrm{O}_{2}^{--}$than chemiluminescent probes. Moreover, lucigenin-based measurements of $\mathrm{O}_{2}^{--}$can cause artifacts in NADPH-rich tissues, such as cardiac or skeletal muscles. ${ }^{36-40}$ The fluorescence probe, dihydroethidium (DHE), is highly sensitive and capable of detecting weak intramuscular $\mathrm{O}_{2}^{\circ-}$ signals in both rodent muscle and myocyte models, whereas chemiluminescence is less adapted in detecting small $\mathrm{O}_{2}^{\circ-}$ signals. ${ }^{1,16,41-45}$ Thus, the fact that $\mathrm{O}_{2}^{--}$production decreased to zero within seconds upon ischemia in Schrader's observation may be possibly due to the lack of sensitivity.

Budd et al. ${ }^{46}$ showed that uncoupler-induced ET fluorescence increase is not due to an increase in $\mathrm{O}_{2}^{--}$production but results from the collapse of the mitochondrial membrane potential, because oxidized DHE (2-hydroxyethidium and ET) behaves as a mitochondrial membrane potential probe. Thus, their research suggested that the loading concentration of DHE should be kept sufficiently low (i.e., $5 \mu \mathrm{M}$ ) in cell culture or mitochondrial suspensions. This dosage is highly consistent with our former study which used the isolated cardiomyocytes. ${ }^{41}$ However, Budd et al. ${ }^{46}$ had a loading condition that was set for the cell culture system (i.e., $5 \mu \mathrm{M}$ for $10 \mathrm{~min}$ ); in our study, we were using a rodent heart, which is comprised of hundreds of tissue layers that required high-loading concentrations compared with that of the cell culture. Although we used a range of $1-10 \mu \mathrm{M}$ of DHE to load the heart, we were unable to detect any signal from the heart during these preliminary tests. Following the previous effective loading protocols for the multilayer muscle tissue, ${ }^{42}$ our current loading concentration is set higher $(44 \mu \mathrm{M})$ and the loading time is set much shorter $(1.5 \mathrm{~min})$ than those of the cells. This procedure is immediately followed by a 5 min washout, to remove excess dye, and a short ischemia protocol. It is worth noting that former research has also shown that it typically requires a longer time (i.e., $60 \mathrm{~min}$ or longer) for a fluorescent probe to successfully load into the mitochondria in cultured cardiomyocytes. ${ }^{47}$ It is likely that the loading time for mitochondria in the whole heart (used in out experiments) may be even longer. Therefore, it is very unlikely 
that within such a short period (1.5 min in our assay) the DHE probe has sufficient time to reach the mitochondrial compartment to cause any artificial signals owing to the collapse of mitochondrial membrane potential.

Conclusion and significance. Through the use of SOD mimic, $\mathrm{CO}$ treatments, and Mb-knockout techniques, we have identified $\mathrm{Mb}$ as a novel $\mathrm{O}_{2}^{\circ-}$ generator in the cardiac myocyte during the onset of ischemia. A small burst of $\mathrm{O}_{2}^{\circ-}$ that was produced by $\mathrm{Mb}$ within $20 \mathrm{~s}$ of ischemia may be correlated with IPC preconditions, though this mechanism has not been thoroughly investigated. For future studies, other biological techniques such as electron paramagnetic resonance may be used to quantify $\mathrm{O}_{2}^{\circ-}$ signals in this model, and explore a more specific role of $\mathrm{Mb}$ in cardiac protection, which facilitates the understanding of the molecular signaling pathways for IPC and $\mathrm{O}_{2}^{\circ-}$ development during ischemia.

\begin{abstract}
Materials and Methods
Rat Langendorff heart perfusion. Male Sprague-Dawley rats weighing $\sim 350 \mathrm{~g}$ were anesthetized with pentobarbital $(\sim 50 \mathrm{mg} / \mathrm{kg}$ intraperitoneal injection). After hemithoractomy, hearts were rapidly excised, and aorta were cannulated under retrograde coronary perfusion at $80 \mathrm{~mm} \mathrm{Hg}$ with Krebs-Henseleit buffer $\left(120.0 \mathrm{mM} \mathrm{NaCl}, 5.9 \mathrm{mM} \mathrm{KCl}, 2.5 \mathrm{mM} \mathrm{CaCl}_{2}, 1.2 \mathrm{mM} \mathrm{MgCl}_{2}, 16.7 \mathrm{mM}\right.$ glucose, $25.0 \mathrm{mM} \mathrm{NaHCO} 3,0.5 \mathrm{mM}$ EDTA, bubbled with $95 \% / 5 \% \mathrm{O}_{2} / \mathrm{CO}_{2}$ ). ${ }^{1}$ Hearts were mounted on a Langendorff perfusion apparatus. Each heart was perfused until the recovery of steady cardiac frequency at $37^{\circ} \mathrm{C}$ for $15 \mathrm{~min}$. Ischemia was induced by the stopping of the flow of perfusate.
\end{abstract}

Mb-knockout mice. Mb-knockout (Myo $-/-$ ) mice were generated by deletion of the essential genes of $\mathrm{Mb}$ in embryonic stem cells, as described previously. ${ }^{48}$ Mice were genotyped when they were weaned. The experimentation was performed using male mice, and tail clips were kept to reconfirm the genotypes. Both Myo - I - and wild-type mice were heparinized $(500 \mathrm{U} / \mathrm{kg})$ and anesthetized via intraperitoneal injection with a combination of ketamine $(70 \mathrm{mg} /$ $\mathrm{kg}$ ) and xylazine $(10 \mathrm{mg} / \mathrm{kg})$. After hemithoractomy, hearts were rapidly excised and mounted in a Langendorff perfusion apparatus following the similar protocol to the rat experiments.

Carbon monoxide perfusion. Carbon monoxide (CO) was used to block the $\mathrm{O}_{2}$ binding to $\mathrm{Mb}$. In addition to the Langendorff heart protocol, $\mathrm{CO}$ was fully equilibrated with gas sampling tube for $20 \mathrm{~min}$. At $37^{\circ} \mathrm{C}$, Krebs-Henseleit buffer flow rate was $16.2 \mathrm{ml} / \mathrm{min}$ and the adjacent tube of $\mathrm{CO}$ had a flow rate of $1.8 \mathrm{ml} /$ min. Thus, the overall CO flow rate was set at $10 \%$ of the total flow rate, which was $18 \mathrm{~m} / \mathrm{min}(16.2+1.8=18)$ for $5 \mathrm{~min}$.

Surface fluorometry. We measured changes in radical formation in the early ischemia in an isolated rodent (rat/mouse) heart. A fiber optic probe was positioned facing the left ventricle in order to obtain an emission signal from the heart. The distance between the heart and cable surface was adjusted to minimize the motion artifact. DHE/ET fluorescence was used as a non-charged $\mathrm{O}_{2}^{--}$sensitive probe. DHE (Molecular Probes/Life Technologies, Grand Island, NY, USA) stock was dissolved in $\mathrm{N}, \mathrm{N}$-dimethylacetamide (Acros Organics/Thermo Fisher Scientific, Waltham, MA, USA). In response to $\mathrm{O}_{2}^{--}$, DHE is dehydrogenated, resulting in the formation of 2-hydroxyethidium, which is relatively unstable and converts to a stabilized ET ${ }^{41,49} \mathrm{ET}$ is positively charged and has better cellular retention and stability when compared with DHE. ${ }^{42}$ Therefore, ET formation was chosen as a reliable indicator of $\mathrm{O}_{2}^{--}$ production. ${ }^{43,44,46}$ The ET excitation filter was set at $515 \pm 20 \mathrm{~nm}$, and the ET emission was set within a range of $590 \pm 25 \mathrm{~nm}$. The emitted fluorescent signal was recorded every $4 \mathrm{~s}$ and then transmitted to a computer through an $A / D$ board. A mean fluorescence rate was used to monitor the ET signal change per second at each specific time. A fresh DHE solution was made before dye injection into the heart. Thus, any oxidation of DHE in the solution that bubbled in $95 \% \mathrm{O}_{2}$ was kept at a minimal..$^{50}$ Hearts were perfused with $44 \mu \mathrm{M}$ DHE for $1.5 \mathrm{~min}$ at a perfusion rate of $1 \mathrm{ml} / \mathrm{min}$, followed by a short global ischemia. To confirm that fluorescence was in fact trigged by a burst of $\mathrm{O}_{2}^{--}$production, a group of hearts were perfused with both the SOD mimic Mn(III)tetrakis(1-methyl-4-pyridyl) porphyrin (MnTMPyP, Enzo Life Sciences/Alexis Biochemicals, Farmingdale, NY, USA; $250 \mu \mathrm{M})$ and DHE before ischemia as negative controls.

Confocal study. Langendorff rat hearts were first perfused with a solution of DHE $(44 \mu \mathrm{M})$ to detect $\mathrm{O}_{2}^{\circ-}$ and fluorescein lectin l-isolectin B4 (FLI-IB4, $0.67 \mu \mathrm{g} / \mathrm{ml}$, Vector Labs, Burlingame, CA, USA) as a marker for intracellular endothelium for $1.5 \mathrm{~min}$ at $1 \mathrm{ml} / \mathrm{min}$. The excess dye was washed out for $5 \mathrm{~min}$ with buffer. Hearts were immobilized by an actin-myosin complex blocker 2,3-butanedione monoxime ( $4 \mathrm{mM}$; Acros Organics), ${ }^{42}$ transferred to the confocal microscope stage, and perfused with $37^{\circ} \mathrm{C}$ buffer for $\sim 5 \mathrm{~min}$ immediately followed by an ischemic period. The confocal images were recorded when the heart was in an ischemia condition.

The set up for laser scan confocal imaging of $\mathrm{O}_{2}^{--}$was the following: Laser: argon; objective, $\times 40$ with 1.5 -mm working distance; ET excitation, $568 \mathrm{~nm}$; ET emission, long pass (LP, $590 \mathrm{~nm})$. The autofluorescence background was kept minimal in the current settings. Images of the emitted fluorescence signals were captured by a photomultiplier tube and transferred to a computer monitor that displayed them at $512 \times 512$ pixels for analysis. ${ }^{1,42}$

Statistical analysis. Data are expressed as mean \pm S.E., unless noted otherwise. The statistical significance of differences between groups was calculated using two-way analysis of variance. The $P$-values of $<0.05$ were considered significant.

\section{Conflict of Interest}

The authors declare no conflict of interest.

Acknowledgements. This work was supported in part by OSU-HRS Fund 013000, by OSU research resources from HRS and DHLRI, by OU General Fund G110 and Research Excellence Fund of Biomedical Research, by Shanghai Ruijin Hospital (China), and by UCSD research resources. We especially acknowledge the assistance of Allison Hallman for research support.

1. Zuo $L$, Chen YR, Reyes $L A$, Lee HL, Chen $C L$, Villamena FA et al. The radical trap 5,5dimethyl-1-pyrroline $\mathrm{N}$-oxide exerts dose-dependent protection against myocardial ischemia-reperfusion injury through preservation of mitochondrial electron transport. $J$ Pharmacol Exp Ther 2009; 329: 515-523.

2. Zuo L, Roberts WJ, Tolomello RC, Goins AT. Ischemic and hypoxic preconditioning protect cardiac muscles via intracellular ROS signaling. Front Biol 2013; 8: 305-311.

3. Galaris D, Eddy L, Arduini A, Cadenas E, Hochstein P. Mechanisms of reoxygenation injury in myocardial infarction: implications of a myoglobin redox cycle. Biochemi Biophy Res Commun 1989; 160: 1162-1168.

4. Galaris D, Cadenas E, Hochstein P. Redox cycling of myoglobin and ascorbate: a potential protective mechanism against oxidative reperfusion injury in muscle. Arch Biochem Biophys 1989; 273: 497-504.

5. Ordway GA, Garry DJ. Myoglobin: an essential hemoprotein in striated muscle. J Exp Biol 2004; 207(Pt 20): 3441-3446.

6. George P, Stratmann CJ. The oxidation of myoglobin to metmyoglobin by oxygen. III. Kinetic studies in the presence of carbon monoxide, and at different hydrogen-ion concentrations with considerations regarding the stability of oxymyoglobin. Biochem $J$ 1954; 57 : 568-573.

7. Reid MB, Haack KE, Franchek KM, Valberg PA, Kobzik L, West MS. Reactive oxygen in skeletal muscle. I. Intracellular oxidant kinetics and fatigue in vitro. J Appl Physiol 1992; 73: 1797-1804.

8. Yang J, Marden JJ, Fan C, Sanlioglu S, Weiss RM, Ritchie TC et al. Genetic redox preconditioning differentially modulates AP-1 and NF kappa B responses following cardiac ischemia/reperfusion injury and protects against necrosis and apoptosis. Mol Ther 2003; 7: 341-353.

9. Zweier JL, Kuppusamy P, Williams R, Rayburn BK, Smith D, Weisfeldt ML et al. Measurement and characterization of postischemic free radical generation in the isolated perfused heart. J Biol Chem 1989; 264: 18890-18895.

10. Thompson-Gorman SL, Zweier JL. Evaluation of the role of xanthine oxidase in myocardial reperfusion injury. J Biol Chem 1990; 265: 6656-6663.

11. Obal D, Dai S, Keith R, Dimova N, Kingery J, Zheng YT et al. Cardiomyocyterestricted overexpression of extracellular superoxide dismutase increases nitric oxide 
bioavailability and reduces infarct size after ischemia/reperfusion. Basic Res Cardiol 2012 107: 305

12. Chen Z, Siu B, Ho YS, Vincent R, Chua CC, Hamdy RC et al. Overexpression of MnSOD protects against myocardial ischemia/reperfusion injury in transgenic mice. $\mathrm{J} \mathrm{Mol} \mathrm{Cell}$ Cardiol 1998; 30: 2281-2289.

13. Wang P, Chen H, Qin H, Sankarapandi S, Becher MW, Wong PC et al. Overexpression of human copper, zinc-superoxide dismutase (SOD1) prevents postischemic injury. Proc Natl Acad Sci USA 1998; 95: 4556-4560.

14. Perrelli MG, Pagliaro P, Penna C. Ischemia/reperfusion injury and cardioprotective mechanisms: role of mitochondria and reactive oxygen species. World J Cardiol 2011; 3: 186-200.

15. Becker LB, vanden Hoek TL, Shao ZH, Li CQ, Schumacker PT. Generation of superoxide in cardiomyocytes during ischemia before reperfusion. Am J Physiol 1999; 277(6 Pt 2): $\mathrm{H} 2240-\mathrm{H} 2246$.

16. Zhu X, Zuo L, Cardounel AJ, Zweier JL, He G. Characterization of in vivo tissue redox status, oxygenation, and formation of reactive oxygen species in postischemic myocardium. Antioxid Redox Signal 2007; 9: 447-455.

17. Brantley RE Jr, Smerdon SJ, Wilkinson AJ, Singleton EW, Olson JS. The mechanism of autooxidation of myoglobin. J Biol Chem 1993; 268: 6995-7010.

18. Saltman P. On and beyond $\mathrm{O} 2$ binding: hemoglobin and myoglobin revisited. Experientia 1995; 51: 205-206.

19. Zuo L, Clanton TL. Reactive oxygen species formation in the transition to hypoxia in skeletal muscle. Am J Physiol Cell Physiol 2005; 289: C207-C216.

20. Li JM, Shah AM. Endothelial cell superoxide generation: regulation and relevance fo cardiovascular pathophysiology. Am J Physiol Regul Integr Comp Physiol 2004; 287: R1014-R1030.

21. Lu Q, Wainwright MS, Harris VA, Aggarwal S, Hou Y, Rau T et al. Increased NADPH oxidase-derived superoxide is involved in the neuronal cell death induced by hypoxiaischemia in neonatal hippocampal slice cultures. Free Radic Biol Med 2012; 53: 1139-1151.

22. Suh SW, Shin BS, Ma H, Van Hoecke M, Brennan AM, Yenari MA et al. Glucose and NADPH oxidase drive neuronal superoxide formation in stroke. Ann Neurol 2008; 64 654-663.

23. Linas SL, Whittenburg D, Repine JE. Role of xanthine oxidase in ischemia/reperfusion injury. Am J Physiol 1990; 258(3 Pt 2): F711-F716.

24. Turrens JF. Mitochondrial formation of reactive oxygen species. J Physiol 2003; 552(Pt 2): 335-344.

25. Braunlin EA, Wahler GM, Swayze CR, Lucas RV, Fox IJ. Myoglobin facilitated oxygen diffusion maintains mechanical function of mammalian cardiac muscle. Cardiovasc Res 1986; 20: 627-636.

26. Gunther MR, Sampath V, Caughey WS. Potential roles of myoglobin autoxidation in myocardial ischemia-reperfusion injury. Free Radic Biol Med 1999; 26: 1388-1395.

27. Cooper CE, Brown GC. The inhibition of mitochondrial cytochrome oxidase by the gases carbon monoxide, nitric oxide, hydrogen cyanide and hydrogen sulfide: chemical mechanism and physiological significance. J Bioenerg Biomembr 2008; 40: 533-539.

28. Raedschelders K, Ansley DM, Chen DD. The cellular and molecular origin of reactive oxygen species generation during myocardial ischemia and reperfusion. Pharmacol Ther 2012; 133: 230-255.

29. Roberts WJ, Zuo L. Hypoxic preconditioning reduces reoxygenation injuries via PI3K in respiratory muscle. GSTF JBio 2012; 2: 42-53

30. Juhaszova M, Zorov DB, Kim SH, Pepe S, Fu Q, Fishbein KW et al. Glycogen synthase kinase-3beta mediates convergence of protection signaling to inhibit the mitochondrial permeability transition pore. J Clin Invest 2004; 113: 1535-1549.

31. Tong H, Imahashi K, Steenbergen C, Murphy E. Phosphorylation of glycogen synthase kinase-3beta during preconditioning through a phosphatidylinositol-3-kinase-dependent pathway is cardioprotective. Circ Res 2002; 90: 377-379.

32. Liu Y, Sato T, O'Rourke B, Marban E. Mitochondrial ATP-dependent potassium channels: novel effectors of cardioprotection? Circulation 1998; 97: 2463-2469.
33. Schulz R, Cohen MV, Behrends M, Downey JM, Heusch G. Signal transduction of ischemic preconditioning. Cardiovasc Res 2001; 52: 181-198.

34. Pain T, Yang XM, Critz SD, Yue Y, Nakano A, Liu GS et al. Opening of mitochondrial K(ATP) channels triggers the preconditioned state by generating free radicals. Circ Res 2000; 87: 460-466.

35. Flogel U, Godecke A, Klotz LO, Schrader J. Role of myoglobin in the antioxidant defense of the heart. FASEB J 2004; 18: 1156-1158.

36. Tarpey MM, Wink DA, Grisham MB. Methods for detection of reactive metabolites of oxygen and nitrogen: in vitro and in vivo considerations. Am J Physiol Regul Integr Comp Physiol 2004; 286: R431-R444

37. Li Y, Zhu H, Kuppusamy P, Roubaud V, Zweier JL, Trush MA. Validation of lucigenin (bis-N-methylacridinium) as a chemilumigenic probe for detecting superoxide anion radical production by enzymatic and cellular systems. J Biol Chem 1998; 273: 2015-2023.

38. Liochev SI, Fridovich I. Lucigenin luminescence as a measure of intracellular superoxide dismutase activity in Escherichia coli. Proc Natl Acad Sci USA 1997; 94: 2891-2896.

39. Vasquez-Vivar J, Hogg N, Pritchard KA Jr., Martasek P, Kalyanaraman B. Superoxide anion formation from lucigenin: an electron spin resonance spin-trapping study. FEBS Lett 1997; 403: 127-130.

40. Barbacanne MA, Souchard JP, Darblade B, lliou JP, Nepveu F, Pipy B et al. Detection of superoxide anion released extracellularly by endothelial cells using cytochrome $C$ reduction, ESR, fluorescence and lucigenin-enhanced chemiluminescence techniques. Free Radic Biol Med 2000; 29: 388-396.

41. Zuo L, Youtz DJ, Wold LE. Particulate matter exposure exacerbates high glucose-induced cardiomyocyte dysfunction through ROS generation. PLoS One 2011; 6: e23116.

42. Zuo L, Christofi FL, Wright VP, Liu CY, Merola AJ, Berliner LJ et al. Intra- and extracellular measurement of reactive oxygen species produced during heat stress in diaphragm muscle. Am J Physiol Cell Physiol 2000; 279: C1058-C1066.

43. Al-Mehdi $A B$, Shuman $H$, Fisher $A B$. Intracellular generation of reactive oxygen species during nonhypoxic lung ischemia. Am J Physiol 1997; 272(2 Pt 1): L294-L300.

44. Nethery D, Stofan D, Callahan L, DiMarco A, Supinski G. Formation of reactive oxygen species by the contracting diaphragm is PLA(2) dependent. J Appl Physiol 1999; 87: 792-800.

45. Zuo L, Clanton TL. Detection of reactive oxygen and nitrogen species in tissues using redox-sensitive fluorescent probes. Methods Enzymol 2002; 352: 307-325.

46. Budd SL, Castilho RF, Nicholls DG. Mitochondrial membrane potential and hydroethidinemonitored superoxide generation in cultured cerebellar granule cells. FEBS Lett 1997; 415: 21-24.

47. Christensen ML, Braunstein TH, Treiman M. Fluorescence assay for mitochondrial permeability transition in cardiomyocytes cultured in a microtiter plate. Anal Biochem 2008; 378: 25-31.

48. Godecke A, Flogel U, Zanger K, Ding Z, Hirchenhain J, Decking UK et al. Disruption of myoglobin in mice induces multiple compensatory mechanisms. Proc Natl Acad Sci USA 1999; 96: 10495-10500.

49. Zielonka J, Hardy M, Kalyanaraman B. HPLC study of oxidation products of hydroethidine in chemical and biological systems: ramifications in superoxide measurements. Free Radic Biol Med 2009; 46: 329-338.

50. Napankangas JP, Liimatta EV, Joensuu P, Bergmann U, Ylitalo K, Hassinen IE. Superoxide production during ischemia-reperfusion in the perfused rat heart: a comparison of two methods of measurement. J Mol Cell Cardiol 2012; 53: 906-915.

(2) ()ㅇ Cell Death and Disease is an open-access journal published by Nature Publishing Group. This work is licensed under a Creative Commons Attribution-NonCommercialNoDerivs 3.0 Unported License. To view a copy of this license, visit http://creativecommons.org/licenses/by-nc-nd/3.0/ 